\title{
Phylogenetic Position of Cowdria ruminantium (Rickettsiales) Determined by Analysis of Amplified 16S Ribosomal DNA Sequences
}

\author{
ARNOUD H. M. VAN VLIET, ${ }^{1}$ FRANS JONGEJAN, ${ }^{2}$ AND BERNARD A. M. VAN DER ZEIJST ${ }^{1 *}$ \\ Departments of Bacteriology ${ }^{1}$ and Parasitology, ${ }^{2}$ Institute of Infectious Diseases and Immunology, \\ School of Veterinary Medicine, University of Utrecht, P.O. Box 80.165, \\ 3508 TD Utrecht, The Netherlands
}

\begin{abstract}
The 16S ribosomal DNA sequence of Cowdria ruminantium, the causative agent of heartwater disease in ruminants, was determined. An analysis of this sequence showed that $C$. ruminantium forms a tight phylogenetic cluster with the canine pathogen Ehrlichia canis and the human pathogen Ehrlichia chaffeensis. Although a close relationship between the genus Cowdria and several members of the tribe Ehrlichieae has been suspected previously, the tight phylogenetic cluster with $E$. canis and $E$. chaffeensis is surprising in view of known differences in host preference and target cells.
\end{abstract}

The rickettsia Cowdria ruminantium is the causative agent of heartwater, a tick-borne disease of wild and domestic ruminants. This disease is endemic in sub-Saharan Africa (28). Recently, Cowdria ruminantium has also been detected in the Caribbean region (28). In view of the continuing spread of the African tick Amblyomma variegatum in the Caribbean (29), heartwater may become a serious threat to livestock on the American mainland (2).

The genus Cowdria is currently classified in the tribe Ehrlichieae in the order Rickettsiales, together with the genera Ehrlichia and Neorickettsia (33). The members of the genus Cowdria share antigenic determinants with several members of the genus Ehrlichia $(5,13,17)$ and also with members of the genus Chlamydia (11): A recent electron microscopic study of the multiplication of Cowdria cells in cultured bovine umbilical endothelial cells showed that the genus Cowdria has developmental stages that resemble those of chlamydial species (14). It has been assumed that the developmental cycle consists of an extracellular stage (extracellular bodies) and an intracellular stage (reticulate bodies). A phylogenetic study of the $16 \mathrm{~S}$ ribosomal DNA (rDNA) of Cowdria ruminantium was initiated to determine the taxonomic relationship of the genus Cowdria with Ehrlichia and Chlamydia species more precisely.

The Senegal stock (12) of Cowdria ruminantium was cultured in bovine umbilical endothelial cells as described previously (10). Escherichia coli K-12 strain PC2495, an $h s d S$ recA derivative of strain JM101 (36), was used for the propagation of $\mathrm{pBS}(-)$ phagemid and derived clones (Stratagene, La Jolla, Calif.) and was grown overnight at $37^{\circ} \mathrm{C}$ in Terrific Broth (27) supplemented with $100 \mu \mathrm{g}$ of ampicillin per $\mathrm{ml}$.

Genomic DNA for polymerase chain reaction amplification was extracted from the extracellular body-containing supernatant of an infected $162-\mathrm{cm}^{2}$ culture (infection score, $2+)(10)$. The supernatant was centrifuged at $15,000 \times g$ for $15 \mathrm{~min}$, the extracellular bodies were suspended in $1 \mathrm{ml}$ of TEG buffer ( $25 \mathrm{mM}$ Tris-HCl [pH 8.0], $10 \mathrm{mM}$ EDTA, 50 mM glucose) supplemented with $4 \mathrm{mg}$ of lysozyme per $\mathrm{ml}$, and the preparation was incubated for $15 \mathrm{~min}$ at room temperature. Sodium dodecyl sulfate and proteinase $\mathbf{K}$ were

\footnotetext{
* Corresponding author.
}

subsequently added to final concentrations of $0.5 \%$ and 400 $\mu \mathrm{g} / \mathrm{ml}$, respectively, and incubation was continued for $1 \mathrm{~h}$ at $55^{\circ} \mathrm{C}$. The DNA was precipitated with isopropanol and then suspended in $\mathrm{H}_{2} \mathrm{O}$.

The 16S rDNA of Cowdria cells was amplified in a total volume of $100 \mu \mathrm{l}$ by using the terminal primers fD1 and rD1 (30) and Taq polymerase (Promega, Madison, Wis.) under conditions described elsewhere $(30)$. The amplification products were characterized by agarose gel electrophoresis. The 1.5-kb 16S rDNA fragment was purified by using a Geneclean kit (Bio 101, La Jolla, Calif.) and was made blunt ended by incubating it for $15 \mathrm{~min}$ at $37^{\circ} \mathrm{C}$ with $E$. coli DNA polymerase I without deoxynucleoside triphosphates and then at $37^{\circ} \mathrm{C}$ for $15 \mathrm{~min}$ with deoxynucleoside triphosphates at concentrations of $1.67 \mathrm{mM}$ (34). The DNA was phenol extracted, ethanol precipitated, and ligated into the EcoRV restriction site of pBS by using T4 DNA ligase. Plasmid DNAs of clones were purified by using the alkaline lysis method followed by cesium chloride-ethidium bromide density gradient centrifugation (23).

The nucleotide sequences of both strands of two cloned amplification products (clones pCRS2 and pCRS5) were determined by using the dideoxy chain termination method (24) and $\left[\alpha^{-32} \mathrm{P}\right] \mathrm{dATP}$. Sequencing reactions were carried out by using a T7 sequencing kit (Pharmacia, Uppsala, Sweden) according to the manufacturer's instructions. The primers used for the sequencing of the 16S rDNA, both forward and reverse, have been described previously (30). A discrepancy between the sequences of clones pCRS2 and pCRS5 was detected at position 1447 ( $G$ and A, respectively). This part of the sequence was also determined for two other clones (pCRS7 and pCRS8), which were derived from a different amplification reaction. Both sequences had $G$ at this position. Therefore, we decided to use $G$ at position 1447 for the phylogenetic analyses. The sequence that was determined in this way is shown in Fig. 1.

Aligned 16S rRNA sequences of $E$. coli, Chlamydia psittaci, and the alpha bacteria were obtained from the smallribosomal-subunit RNA data base (R. De Wagter, University of Antwerp, Antwerp, Belgium) (20). Other 16S rRNA sequences were obtained from the EMBL and GenBank data bases. The 16S rRNA sequences of Cowdria ruminantium, Anaplasma marginale (30), and the Ehrlichia species (1) were aligned with the small-ribosomal-subunit RNA align- 


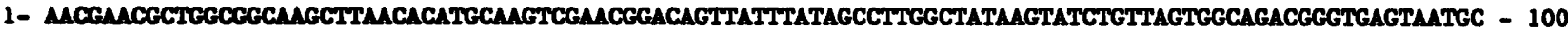

101- GTAGGMTCTECCTAGTAGTATEGMTAGCTATTAGMATGATAGGTAATACTCTATAATCCTGCGGGGGAAGATTTATCGCTATTAGATGAGCCTACG - 200

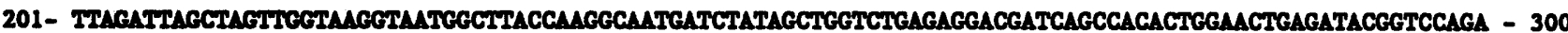

301- CTCCTACGCGACGAGCAOTGGCGATATTEGACMTGGGCGM

401- TIAMTAGGQMGATAMGACGGTACCTATAGMMMGTCCCGGGMCTCCGTGCGAGCAGCCGCCGTATACGGAGGGGGCAGCGTTGTTCGGATTA - 500

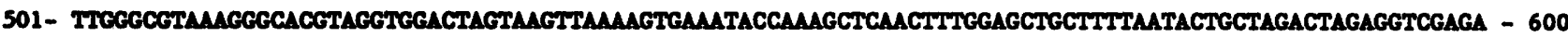

601- GAGGATAGCGGMTTCCTAGTGTAGAGGTGAATTCGTAGATATIAGGAGgAGACCGGTGGCGAGGCGGCTATCTEGCTCGATACTGACACTGAGGTE - 700

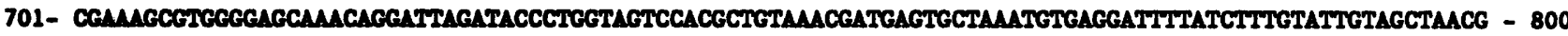

801- COTTMACACTCCGCCTCGGGACTACEGTCGCAMACTAMACTCAMGGATTGACGGGGACCCGCACAAGCGGTGGACCATGTGGTTTAATCGATGC - 900

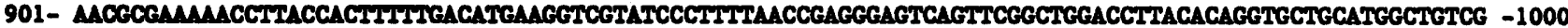

1001- TCAGCTCETGTCGTEAGATGTTGGGTTAGTCCCGCAACAGCGCAACCCTCATCCTTAGTTACGAACAGGTAATGCTGGGACTCTAAGGAACTGCGA -1100

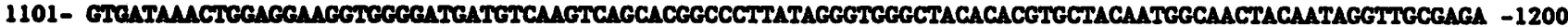

1201- CCOCOAGGTTACCTMATCCMMMMGTTGTCTGAGTTCGGATTTTCTCTGGAACTCGAGAGGATGAGTCGGMTCGCTAGTATCGTGGATCATCAT -1300

1301- GCC1CGOTGATACETTCTCGEGTCTTGTACACACTGCCCETCACGCCATGGGATTGGCITAACTCGAGCTGGTGTGCTAACCGTAAGGAGCAGCCA -1400

1401- TITMACGTTGGTTAGTGACTAGGGTGAGTCGTAMCAAGGTAGCTGTAGGTGAACC

$-1457$

FIG. 1. Nucleotide sequence of the 16S rRNA gene of Cowdria ruminantium. The nucleotide sequences of the polymerase chain reaction primers that were used to amplify the sequenced fragment are not shown.

ment (20). Because the eubacterial sequences in this alignment were aligned with eucaryotic, plastidial, mitochondrial, and archaebacterial small-ribosomal-subunit sequences, the alignment was processed to eliminate positions where all of the 16S rRNA sequences which we used had a gap. This alignment was used for a sequence signature analysis (35) and phylogenetic analyses. Additional sequence masking that eliminated all positions where sequences had gaps, which allowed us to use only positions that were represented in all sequences, affected only the length of the branches in the evolutionary distance trees, not the branching order (data not shown).

The phylogenetic analyses which we performed were distance matrix and parsimony analyses, as described in the Felsenstein-Phylip package, version $3.3(8)$. The treeing algorithms that assumed no evolutionary clock which we used with the distance matrix were the Fitch (9), NJTree (22), and UPGMA (26) algorithms. A treeing algorithm that assumed an evolutionary clock which we used with the distance matrix was the Kitsch program (9). The evolutionary distance trees that were generated by these programs and the trees that were generated by the parsimony analysis program DNAPars (7) were not significantly aberrant from the tree shown in Fig. 2. This evolutionary distance tree was generated by using the distance matrix from the analyses performed without a sequence mask (Table 1), using the Fitch program.

An analysis of the helices between positions 180 and 220 ( $E$. coli numbering) (20) indicated that the genus Cowdria is related to the alpha subdivision of the purple bacteria (35). The sequence signature analysis showed that the 16S rRNA sequence of the genus Cowdria matches the signature sequences of the alpha subgroup of the purple bacteria in 58 of 66 positions (35), and similarity data and evolutionary distance data showed that the genus Cowdria is related to other

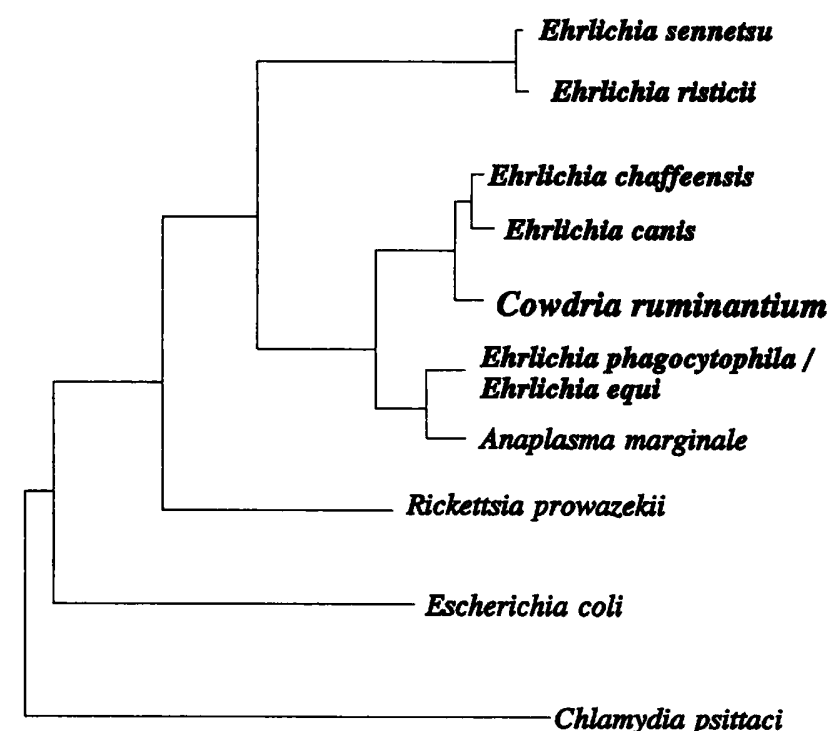

\begin{tabular}{cccccc}
0.00 & 0.05 & 0.10 & 0.15 & 0.20 & 0.25 \\
& \multicolumn{5}{c}{ Evolutionary distance }
\end{tabular}

FIG. 2. Evolutionary distance tree showing the relationships among ehrlichial and rickettsial species. All of the species belonging to the tribe Ehrlichieae are shown in boldface type. The tree was constructed by using the evolutionary distances shown in Table 1. 
TABLE 1. Percentages of sequence identity and evolutionary distances among ehrlichial, chlamydial, and other eubacterial rRNA and rDNA sequences

\begin{tabular}{|c|c|c|c|c|c|c|c|c|c|c|c|}
\hline \multirow[b]{2}{*}{ Organism } & \multicolumn{11}{|c|}{$\%$ Sequence identity and evolutionary distance $\left(10^{-2}\right)^{a}$} \\
\hline & $\begin{array}{l}\text { Cowdria } \\
\text { ruminantium }\end{array}$ & $\begin{array}{c}\text { Ehrlichia } \\
\text { canis }\end{array}$ & $\begin{array}{l}\text { Ehrlichia } \\
\text { chaffeensis }\end{array}$ & $\begin{array}{c}\text { Ehrlichia } \\
\text { phago- } \\
\text { cytophila }\end{array}$ & $\begin{array}{c}\text { Ehrlichia } \\
\text { equi }\end{array}$ & $\begin{array}{l}\text { Ehrlichia } \\
\text { risticii }\end{array}$ & $\begin{array}{l}\text { Ehrlichia } \\
\text { sennetsu }\end{array}$ & $\begin{array}{c}\text { Anaplasma } \\
\text { marginale }\end{array}$ & $\begin{array}{c}\text { Rickettsia } \\
\text { prowazekii }\end{array}$ & $\begin{array}{l}\text { Escherichia } \\
\quad \text { coli }\end{array}$ & $\begin{array}{c}\text { Chlamydia } \\
\text { psittaci }\end{array}$ \\
\hline Cowdria ruminantium & & 96.8 & 97.0 & 92.2 & 92.1 & 83.0 & 83.3 & 92.1 & 81.4 & 75.8 & 71.7 \\
\hline Ehrlichia canis & 2.4 & & 98.1 & 92.3 & 92.3 & 82.4 & 83.1 & 91.9 & 80 & 74.7 & 71.3 \\
\hline Ehrlichia chaffeensis & 2.0 & 1.4 & & 92.7 & 92.7 & 82.6 & 83.3 & 91.8 & 80.7 & 74.9 & 71.9 \\
\hline Ehrlichia phagocytophila & 7.2 & 7.5 & 7.0 & & 99.9 & 83.4 & 83.9 & 96.2 & 83.4 & 76.5 & 72.3 \\
\hline Ehrlichia equi & 7.2 & 7.6 & 7.1 & 0.1 & & 83.3 & 83.8 & 96.2 & 83.3 & 76.5 & 72.3 \\
\hline Ehrlichia risticii & 17.6 & 18.2 & 17.7 & 16.5 & 16.6 & & 99.0 & 83.8 & 81.7 & 76.4 & 71.9 \\
\hline Ehrlichia sennetsu & 17.3 & 17.9 & 17.4 & 16.5 & 16.5 & 0.5 & & 83.4 & 81.1 & 75.7 & 71.2 \\
\hline Anaplasma marginale & 7.1 & 7.3 & 7.0 & 2.6 & 2.7 & 17.2 & 17.1 & & 82.6 & 77.8 & 72.9 \\
\hline Rickettsia prowazekii & 19.2 & 20.0 & 19.8 & 18.9 & 19.0 & 20.4 & 20.2 & 19.2 & & 77.4 & 74.4 \\
\hline Escherichia coli & 27.9 & 29.3 & 28.6 & 26.3 & 26.4 & 28.1 & 28.1 & 26.1 & 26.4 & & 72.9 \\
\hline Chlamydia psittaci & 34.2 & 34.7 & 33.8 & 32.9 & 33.0 & 35.3 & 35.4 & 32.9 & 31.1 & 32.2 & \\
\hline
\end{tabular}

${ }^{a}$ The values on the upper right are percentages of sequence identity, and the values on the lower left are evolutionary distances.

members of the order Rickettsiales within the alpha subdivision of the purple bacteria. The closest relatives of the genus Cowdria are Ehrlichia canis, the causative agent of canine ehrlichiosis (21), and the recently described human pathogen Ehrlichia chaffeensis (1, 3) (Fig. 2). The members of this phylogenetic cluster exhibited a level of sequence identity of 97 to $98 \%$, which was greater than the level of sequence identity between the $16 \mathrm{~S}$ rRNAs of two species of the genus Chlamydia (95.5\%) (32). More distantly related (92\% sequence identity) are the granulocytic members of the tribe Ehrlichiae, Ehrlichia phagocytophila and Ehrlichia equi (which have recently been reported to be members of the same species) (1), and the erythrocyte-borne rickettsia Anaplasma marginale. Sequence signatures that link the genus Cowdria with the genus Ehrlichia and with Anaplasma marginale and distinguish the genus Cowdria from a set of other bacteria belonging to the alpha subdivision are shown in Table 2.

The genus Ehrlichia has been reported previously to be phylogenetically diverse (1). The close relationship among

TABLE 2. Sequence signature positions that link the genera Cowdria and Ehrlichia with Anaplasma marginale and distinguish this group from other alpha subgroup species

\begin{tabular}{ccc}
\hline Position in & \multicolumn{2}{c}{ Nucleotide in: } \\
\cline { 2 - 3 } 16S rDNA $^{a}$ & $\begin{array}{c}\text { Cowdria, Ehrlichia, and } \\
\text { A. marginale }\end{array}$ & $\begin{array}{c}\text { Other alpha } \\
\text { bacteria }^{b}\end{array}$ \\
\hline 501 & U & C \\
829 & A & G \\
859 & U & C \\
890 & C & G \\
904 & C & U \\
929 & A & G \\
1163 & A & G \\
1246 & C & U \\
1388 & U & C \\
\hline
\end{tabular}

${ }^{a}$ Position (E. coli numbering) (20) at which the 16S rRNA sequences of Cowdria, Ehrlichia, and $A$. marginale have a common composition that differs from the common composition of a collection of $1016 \mathrm{~S}$ rDNA sequences from other bacteria belonging to the alpha subdivision of the purple bacteria.

${ }^{b}$ The alpha bacteria which we used were Agrobacterium tumefaciens, Aquaspirillum magnetotacticum, Brucella abortus, Hyphomicrobium vulgare, Rhodobacter capsulatus, Rhodomicrobium vannielli, Rhodopseudomonas acidophila, Rickettsia prowazekii, Rickettsia rickettsii, Rickettsia typhi, and Rochalimaea quintana. the genus Cowdria, Ehrlichia canis, and Ehrlichia chaffeensis was not expected on the basis of host preference and target cells. Members of the genus Cowdria infect endothelial cells of capillaries and larger blood vessels (28) and to a lesser extent granulocytes (18), whereas Ehrlichia canis infects only canine monocytes (21). Although the target cells for Ehrlichia chaffeensis are not yet known (3), morulae that resemble ehrlichial inclusions have been reported in human monocytes (19).

The results of studies on the serological cross-reactivity between members of the genus Cowdria and members of the tribe Ehrlichiae support the phylogenetic relationship which we observed. For instance, cross-reactive antibodies have been reported between members of the genus Cowdria and Ehrlichia canis, Ehrlichia equi (17), or Ehrlichia phagocytophila (13), but not between members of the genus Cowdria and the more distantly related species Ehrlichia risticii and Ehrlichia sennetsu (17). Cowdria antigens have been used to detect antibodies to Ehrlichia canis by immunofluorescence (6). Although studies on possible serological cross-reactivity between the genus Cowdria and Ehrlichia chaffeensis have not been conducted, it is known that Ehrlichia canis and Ehrlichia chaffeensis are serologically strongly cross-reactive, both in immunofluorescence tests and in Western blotting tests $(3,19)$. Moreover, Ehrlichia canis antigen can be used to detect human ehrlichiosis, which is presumably caused by Ehrlichia chaffeensis (4).

Cowdria ruminantium (16), Ehrlichia canis (25), Ehrlichia phagocytophila (21), and Anaplasma marginale (15) all develop within target cells of several species of ixodid ticks. For the more distantly related organisms Ehrlichia risticii and Ehrlichia sennetsu no vector has been identified yet. In view of the $99.9 \%$ rRNA similarity between Ehrlichia equi and the tick-borne fever-causing organism Ehrlichia phagocytophila (1), we expect that vector transmission of Ehrlichia equi occurs. Although it is suggestive that one-third of the patients with human ehrlichiosis have a history of tick bites before the onset of illness, tick transmission has not been conclusively demonstrated (3). We postulate that the closely related rickettsial organisms may have evolved from common ancestors that originated in their invertebrate tick hosts.

Finally, although the developmental stages of the genus Cowdria resemble those of chlamydial species (14) and common antigenic determinants have been found (11), we 
found no significant phylogenetic relationship (Fig. 2 and Table 1).

The tight clustering of the genus Cowdria with Ehrlichia canis and Ehrlichia chaffeensis indicates that the present subdivision of the tribe Ehrlichieae needs readjustment. Before this matter can be fully addressed, the 16S rRNA sequences of other stocks of Cowdria strains (for instance, the mouse-pathogenic Kümm, Kwanyanga, and Nonile stocks) will have to be determined, as will the sequences of other possibly closely related ehrlichial species, such as Ehrlichia bovis, Ehrlichia ondiri, and Ehrlichia ovis. The fact that the erythrocytic rickettsia Anaplasma marginale (30) clusters with the granulocytic genus Ehrlichia (Fig. 2) and the previously reported phylogenetic diversity of the rickettsiae (31) indicate the need for a reorganization of the order Rickettsiales. Before this can be done, the 16S rRNA sequences of more rickettsial species that are currently placed in three families of the Rickettsiales (Rickettsiaceae, Bartonellaceae, and Anaplasmataceae) will also have to be taken into account.

Cross-reactivity between members of the genus Cowdria and members of the genus Ehrlichia should be further investigated and should be taken into account in studies on the serological diagnosis of cowdriosis and ehrlichial diseases.

Nucleotide sequence accession number. The nucleotide sequence of the amplified 16S rDNA of Cowdria ruminantium has been assigned accession number X62432.

This work was supported by a grant from the Office International des Epizooties, Paris, France. The use of services and facilities of the Dutch National NWO/SURF Expertise Center CAOS/CAMM under grants SON 326-052 and STW-NCH-99.1751 is gratefully acknowledged.

We thank B. E. Anderson for making the Ehrlichia 16S rRNA sequences available.

\section{ADDENDUM IN PROOF}

The 16S ribosomal DNA sequence of the Crystal Springs isolate of Cowdria ruminantium has been reported recently by Dame et al. (J. B. Dame, S. M. Mahan, and C. A. Yowell, Int. J. Syst. Bacteriol. 42:270-274, 1992). The two sequences differ by only 4 nucleotides.

\section{REFERENCES}

1. Anderson, B. E., J. E. Dawson, D. C. Jones, and K. H. Wilson. 1991. Ehrlichia chaffeensis, a new species associated with human ehrlichiosis. J. Clin. Microbiol. 29:2838-2842.

2. Barré, N., G. Uilenberg, P. C. Morel, and E. Camus. 1987. Danger of introducing heartwater onto the American mainland: potential role of indigenous and exotic Amblyomma ticks. Onderstepoort J. Vet. Res. 54:405-417.

3. Dawson, J. E., B. E. Anderson, D. B. Fishbein, J. L. Sanchez, C. S. Goldsmith, K. H. Wilson, and C. W. Duntley. 1991. Isolation and characterization of an Ehrlichia sp. from a patient diagnosed with human ehrlichiosis. J. Clin. Microbiol. 29:27412745.

4. Dawson, J. E., Y. Rikihisa, S. Ewing, and D. B. Fishbein. 1991. Serologic diagnosis of human ehrlichiosis using two Ehrlichia canis isolates. J. Infect. Dis. 163:564-567.

5. Du Plessis, J. L., E. Camus, P. T. Oberem, and L. Malan. 1987. Heartwater serology: some problems with the interpretation of results. Onderstepoort J. Vet. Res. 54:327-329.

6. Du Plessis, J. L., N. Fourie, P. W. Nel, and D. N. Evezard. 1990. Concurrent babesiosis and ehrlichiosis in the dog: blood smear examination supplemented by the indirect fluorescent antibody test, using Cowdria ruminantium as antigen. Onderstepoort J. Vet. Res. 57:151-155.

7. Eck, R. V., and M. O. Dayhoff. 1966. Atlas of protein sequence and structure. National Biomedical Research Foundation, Silver Spring, Md.

8. Felsenstein, J. 1985. Confidence limits on phylogenies: an approach using the bootstrap. Evolution 39:783-791.

9. Fitch, W. M., and E. Margoliash. 1967. Construction of phylogenetic trees. Science 155:279-284.

10. Jongejan, F. 1991. Protective immunity to heartwater (Cowdria ruminantium infection) is acquired after vaccination with in vitro-attenuated rickettsiae. Infect. Immun. 59:729-731.

11. Jongejan, F., R. Bax, M. J. M. Meddens, and W. G. V. Quint. 1991. Cowdria ruminantium is recognized by a monoclonal antibody directed against the major outer membrane protein of Chlamydia trachomatis. Vet. Microbiol. 27:115-123.

12. Jongejan, F., G. Uilenberg, F. F. J. Franssen, A. Gueye, and J. Nieuwenhuijs. 1988. Antigenic differences between stocks of Cowdria ruminantium. Res. Vet. Sci. 44:186-189.

13. Jongejan, F., L. A. Wassink, M. J. C. Thielemans, N. M. Perié, and G. Uilenberg. 1989. Serotypes in Cowdria ruminantium and their relationship with Ehrlichia phagocytophila determined by immunofluorescence. Vet. Microbiol. 21:31-40.

14. Jongejan, F., T. A. Zandbergen, P. A. van de Wiel, M. de Groot, and G. Uilenberg. 1991. The tick-borne rickettsia Cowdria ruminantium has a Chlamydia-like developmental cycle. Onderstepoort J. Vet. Res. 58:227-237.

15. Kocan, K. M. 1986. Development of Anaplasma marginale Theiler in ixodid ticks: coordinated development of a rickettsial organism and its tick host, p. 472-505. In J. R. Sauer and J. A. Hair (ed.), Morphology, physiology and behavioral biology of ticks. Ellis Horwood Ltd., Chichester, England.

16. Kocan, K. M., and J. D. Bezuidenhout. 1987. Morphology and development of Cowdria ruminantium in Amblyomma ticks. Onderstepoort J. Vet. Res. 54:177-182.

17. Logan, L. L., C. J. Holland, C. A. Mebus, and M. Ristic. 1986. Serological relationship between Cowdria ruminantium and certain Ehrlichia. Vet. Rec. 119:458-459.

18. Logan, L. L., T. C. Whyard, J. C. Quintero, and C. A. Mebus. 1987. The development of Cowdria ruminantium in neutrophils. Onderstepoort J. Vet. Res. 54:197-204.

19. McDade, J. E. 1990. Ehrlichiosis-a disease of animals and humans. J. Infect. Dis. 161:609-617.

20. Neefs, J. M., Y. Van de Peer, L. Hendriks, and R. de Wachter. 1990. Compilation of small ribosomal subunit RNA sequences. Nucleic Acids Res. 18:2237-2317.

21. Rikihisa, Y. 1991. The tribe Ehrlichieae and ehrlichial diseases. Clin. Microbiol. Rev. 4:286-308.

22. Saitou, N., and M. Nei. 1987. A neighbour-joining method: a new method for constructing phylogenetic trees. Mol. Biol. Evol. 44:406-425.

23. Sambrook, J., E. F. Fritsch, and T. Maniatis. 1989. Molecular cloning, a laboratory manual, 2nd ed. Cold Spring Harbor Laboratory, Cold Spring Harbor, N.Y.

24. Sanger, F., S. Nicklen, and A. R. Coulson. 1977. DNA sequencing with chain-terminating inhibitors. Proc. Natl. Acad. Sci. USA 85:3608-3612.

25. Smith, R. D., D. M. Sells, E. H. Stephenson, M. Ristic, and D. L. Huxsoll. 1976. Development of Ehrlichia canis, causative agent of canine ehrlichiosis, in the tick Rhipicephalus sanguineus and its differentiation from a symbiotic rickettsia. Am. J. Vet. Res. 37:119-126.

26. Sneath, P. H. A., and R. R. Sokal. 1973. Numeral taxonomy. W. H. Freeman, San Francisco.

27. Tartof, K. D., and C. A. Hobbs. 1987. Improved media for growing plasmid and cosmid clones. Bethesda Res. Lab. Focus 9:12.

28. Uilenberg, G. 1983. Heartwater (Cowdria ruminantium infection): current status. Adv. Vet. Sci. Comp. Med. 27:427-480.

29. Uilenberg, G. 1990. Extension de la tique Amblyomma variegatum dans les Antilles: comment expliquer cette grave menace et que faire? Rev. Elev. Med. Vet. Pays Trop. 43:297-299.

30. Weisburg, W. G., S. M. Barns, D. A. Pelletier, and D. J. Lane. 
1991. 16S ribosomal DNA amplification for phylogenetic study. J. Bacteriol. 173:697-703.

31. Weisburg, W. G., M. E. Dobson, J. E. Samuel, G. A. Dasch, L. P. Mallavia, O. Baca, L. Mandelco, J. E. Sechrest, E. Weiss, and C. R. Woese. 1989. Phylogenetic diversity of the rickettsiae. J. Bacteriol. 171:4202-4206.

32. Weisburg, W. G., T. P. Hatch, and C. R. Woese. 1986. Eubacterial origin of the chlamydiae. J. Bacteriol. 167:570-574.

33. Weiss, E., and J. W. Moulder. 1984. Order I. Rickettsiales Gieszczkiewicz 1939, 25 ${ }^{\mathrm{AL}}$, p. 687-729. In N. R. Krieg and J. G.
Holt (ed.), Bergey's manual of systematic bacteriology, vol. 1. The Williams \& Wilkins Co., Baltimore.

34. Williams, J. F. 1989. PCR questions and answers. Amplifications 3:19.

35. Woese, C. R. 1987. Bacterial evolution. Microbiol. Rev. 51:221271.

36. Yanisch-Perron, C., J. Vieira, and J. Messing. 1985. Improved M13 phage cloning vectors and host strains: nucleotide sequences of the M13mp18 and pUC19 vectors. Gene 33:103119. 